\title{
BOOS BSTIETIS
}

Natural Resources Measurements, 2nd Edition. By Thomas Eugene Avery. McGraw-Hill Book Company, New York, N.Y. 10020. 1975. 339 p. $\$ 12.95$.

This text is an extension of Dr. Avery's 1967 edition of Forest Measurements. It has been expanded to include not only timber estimation techniques but also measurements about rangelands, wildlife, fisheries, water, and outdoor recreation.

The text is organized into three parts. Part One discusses elementary statistical processes, land measurements including measurement units, and elementary photogrammetry. There is a good introduction to statistical decision theory in Chapter 2, just enough to excite the curiosity of the serious student about the land management decision-making process. Also in Chapter 2, the hazards of interpreting the meaning of correlation coefficients is discussed, an item hardly seen outside statistical texts.

Part Two, over one-third of the total text, deals with timber measurements and the traditional ways of securing those measurements. Some reference is made to applications of recent research results on use of aerial photographs for timber resource inventories such as use of large scale photos for tree species identification. As stated earlier in the text, "We have continued to use archaic methods and measurement units for scaling logs and inadequate or inefficient sampling techniques for estimating a host of other resource parameters. The continued need for professional resource managers with imagination and inventiveness is obvious." This statement is also apropos in relation to other resource measurements as they are presented in the succeeding chapters of Part Three.

Part Three consists of six chapters, five dealing with assessment of nontimber resources-range, wildlife, fisherics, watcr, and recreation. The discussions about these assessments are quite cursory and present primarily the traditional ways of inventorying those resources. There have been new techniques developed recently, such as use of the electronic capacitance meter for estimating standing crop biomass and large scale aerial photographs for evaluating plant communities. However, since the intent of the text is to present operational procedures for resource measurements, and these techniques are quasi-operational, only mention of them is justified.

The last chapter deals with dendrochronology. The author presents interesting ideas on how dendrochronology could be eased to evaluate historical climatic events that might give insight on natural resource values.

Unfortunately, not much is said about multiresource inventories and assessments, especially integration of resource values for interpretation to alternative management strategies. This process is a difficult evaluation procedure. The author does emphasize the need to develop valid techniques by which benefits of varied resource outputs can be gauged simultaneously.

The text is a valuable asset to the library of students and practicing land managers for reference to introductory resource assessment techniques. The chapter references have been quite discretely selected to guide the student and manager to more complete explanations of resource measurement techniques. In this context, as the author states, "The resource manager who expects to comprehend and evaluate (resource measurement systems) must adopt a disciplined and critical reading habit for scientific literature."-Richard S. Driscoll, Fort Collins, Colorado.

Forage Management in the North. By Dale Smith. Kendall Hunt Publishing Co., 2460 Kerper Boulevard, Dubuque, Iowa 52001. 237 p., 1975. \$7.50.

This book is a comprehensive approach to the science of forage production and utilization. It is strong on plant physiology but also involves the reader in soil science, chemistry, and pasture and range management practice.

Although it deals specifically with forage management in the northcentral states, the technology and many of the practices and principles could be applied to pastures and rangeland throughout the nation.

The organization of this text is very practical. It starts with a brief discussion of the geographic area and proceeds through soils, seeding and establishment, weed control, the physiology of common legumes and grasses, feed values, and management practices.

The author has taken a cause and effect approach in his discussions. The interrelationship of soil, climate, and plant factors is quite thorough. Plant species requirements, tolerances, nutritional values, and yields are presented and documenting experiments cited.

Seeding and establishment includes data on seedbed preparation, sowing rates by species, season to seed, use of companion crops, inoculation of legumes, seed viability, and the value of seed mixtures.

The weed control chapter stresses the need for clean seed and crop rotations. Problems common to forage legumes and pasture grasses are enumerated. The use of chemicals and the expected results are discussed, differentiating between legumes and grasses. Some herbicide application rates are listed and the results evaluated.

Three chapters are devoted to the effects of winter weather on forage plants. One deals with plant survival and related climatic conditions that may result in forage stand losses. Another goes into some detail on what happens to individual plant cells during cold weather. The third chapter discusses management practices and recommendations which can be implemented to minimize winter kill.

The plant nutrition and growth section presents the reader with a brief relatively complete refresher course in plant physiology. Plant functions and responses are delineated and environmental influences described. A con- 
siderable amount of technological data is presented in this chapter.

Chapters 9 through 23 are concerned with the characteristics of 15 legume and grass species commonly grown as forage in the northcentral United States. Such things as origin, varieties, suitability, yields, response to harvest techniques, disease, and insect problems are discussed.

Many interesting reasons and causes of variation in the composition of forage are presented. Included are the effects of fertilization, soil fertility, temperature, light, climate, and stage of plant development. The final sections of this book are agronomic and management oriented. The need for pasture renovation is expressed, as are the benefits which result.

The chapters on pasture and range management are similar in some ways such as acceptable grazing methods, plant responses, weed problems, and soil factors. However, differences between pasture and range, such as botanical composition, forage yields, stocking rates, climate, and revegetation techniques, are brought out. This is helpful in the mid-west, where range and pasture may overlap.

The sequential arrangement and presentation of material throughout the book are good. Key subjects are emphasized by using italics on the first sentence of each such discussion. This adds greatly to the value of this text as a quick reference.

The author presents many photos, diagrams, and tables throughout, again adding to the utility of the text. The tables and graphs are straightforward and well placed in relation to the written information.

Each chapter is well referenced, providing the reader with additional sources of data on all pertinent subjects.

Any farmer, rancher, land manager, stockman or student should find $\mathrm{Fo}$ rage Management in the North a valuable tool in his day to day operations. It contains much information in an easy to read and understand presentation.-William C. Troxel, Carbondale, Illinois.

The Vampire Bat: A Field Study in Behavior and Ecology 1975. By Dennis C. Turner. The Johns Hopkins University Press, Baltimore, Maryland 21218. 1975. $148 \mathrm{p}$.

This book apparently is an outcome of doctoral research by Dr. Turner at Johns Hopkins University, although the point is not clarified in the acknowledgements.

It may be considered an unusual piece of research for review in this journal on three counts:

1. Its primary hypothesis is from theoretical ecology, namely that selectivity in dietary habit (of vampires in this case) should increase as food supplied (blood of cattle) increases.

2. The methodology emphasis is on the predator (the bat), not the prey

\section{CLYDE ROBIN}

NATIVE SEEDS

\author{
Castro Valley, California 94546
}

\section{DO YOU HAVE THESE FROM SRM?}

Send for the missing ones from SRM, 2120 S. Birch St., Denver, Colo. 80222. Just cut out (or make a copy) of this announcement, check the publications you wish, and put your name and address at the bottom. All prices are postpaid.

Rangeland Hydrology $(\$ 1.75)$

Rangeland Entomology (\$2.25)

Rangeland Reference Areas (\$1.50)

I mproved Range Plants (\$1.75)

Glossary of Terms Used in Range Management (\$1.25)

Arid Shrublands: Proceedings of the Third Workshop of the US/Australia

Rangelands Panel $(\$ 3.00)$

The Jornada Experimental Range (\$2.00) (the cow) and is that of the ethologist, not the range manager.

3. The literary style is uncommon in that verbage seems to have been increased rather than decreased by incessant use of the personal pronoun.

Notwithstanding, it is a useful pioneering work on control of paralytic rabies in cattle, the major husbandry problem for cattlemen in the New World tropics. Its utility lies in the cautions it erects for any cattleman in the tropics about to deal with his vampire-bornc rabies problems. They are:

1. The array and balance of factors causing one rancher's problem may not be the same as his neighbor's-it probably is so different as to require a different solution.

2. Direct assault on the bats themselves, either in their roosts or as they forage, probably will be the most expensive and least effective means of establishing control.

3. A cleverly flexible combination of control techniques probably will include a pasture rotation system; a controlled mixture of cattle breeds, sexes, and ages per herd; and some use of rabies vaccines and intrarumen injection of anticoagulants.

4. An effectively clever mix of control techniques will depend on a continuing inventory of bat bites on the livestock and of the number, location, and size of nearby bat roosts.

Turner's book reminds us that theoretical biologists can relate to our problems of management. $-R$. $B$. Davis, Kingsville, Texas.

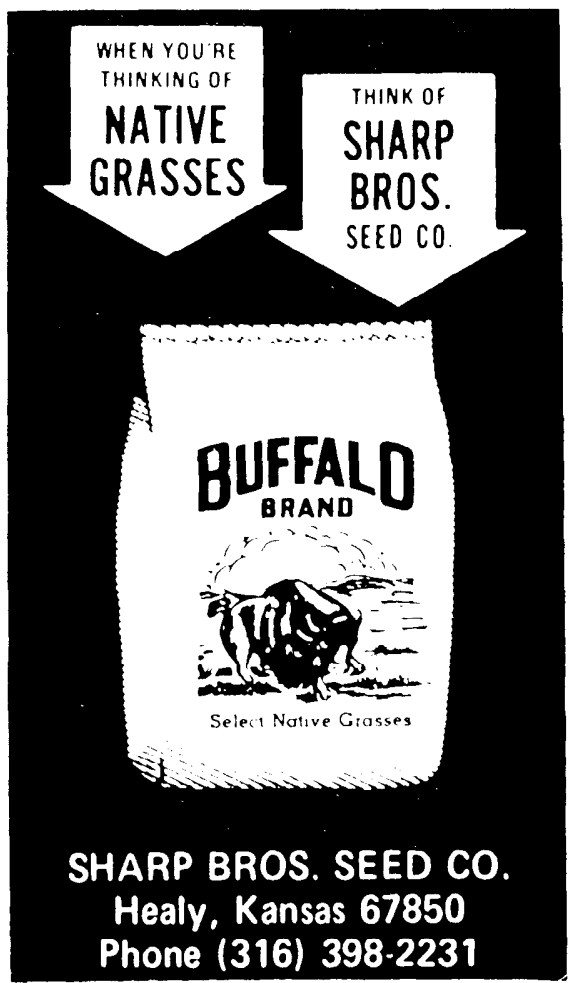

